\title{
Autonomía financiera local
}

\section{Local financial autonomy}

\author{
Juan Martín Queralt \\ Universitat de València (España) \\ jmartinqueralt@martinqueralt.com
}

\section{NOTA BIOGRÁFICA}

Licenciado en Derecho por la Universidad de Valencia y Doctor en Derecho, con Premio Extraordinario, por la Universidad de Bolonia (Italia). Doctor Honoris Causa por la Universidad Jaume I de Castellón. Es Catedrático de Derecho Financiero y Tributario por la Universidad de Valencia y Murcia. Abogado en ejercicio.

\section{RESUMEN}

La previsión constitucional sobre la autonomía financiera local clave sobre la que se asienta la autonomía política ha tenido un dispar desarrollo legislativo. En el ámbito del gasto público se ha fortalecido sensiblemente esa autonomía. Por el contrario en el ámbito del ingreso, la suficiencia financiera depende sustancialmente de fuentes estatales y en menor medida de la correspondiente Hacienda autonómica. El sistema tributario local está necesitado de una revisión en profundidad que lo haga plenamente apto para la financiación de sus competencias. Los fallos judiciales ponen de relieve la necesidad de esa modificación del sistema tributario local. Lo que ha pasado con las Sentencias sobre el Impuesto de Plusvalía es un claro ejemplo de ello.

\section{PALABRAS CLAVE}

Autonomía local; suficiencia financiera; ingresos tributarios; gasto público.

\begin{abstract}
The constitutional forecast on the key local financial autonomy on which political autonomy is based has had a uneven legislative development. In the area of public expenditure, this autonomy has been significantly strengthened. By contrast, in the area of revenue, financial adequacy depends substantially on state sources and to a lesser extent than the corresponding Autonomous Treasury. The local tax system needs of an in-depth review to makes it fully adecuate for financing of their competences. Judicial decisions highlight the need for such modification of the local tax system. What has happened with the Judgements on Capital Gains Tax is a clear example of this.
\end{abstract}

\section{KEYWORDS}

Local autonomy; financial sufficiency; tax revenue; public spending.

\section{SUMARIO}

1. EL PUNTO DE PARTIDA. 2. AUTONOMÍA VERSUS SUFICIENCIA. 3. LOS PERCANCES JUDICIALES Y EL DESEQUILIBRIO DEL SISTEMA DE INGRESOS PÚBLICOS LOCALES. 4. LA DESIDIA DEL LEGISLADOR ESTATAL. 5. LA AUTONOMÍA LOCAL EN MATERIA DE GASTO. 6. CONCLUSIONES. 


\section{EL PUNTO DE PARTIDA}

Reflexionar acerca de la autonomía financiera local equivale a pensar sobre uno de los sectores de nuestro ordenamiento que ha experimentado una menor transformación tras la entrada en vigor de la Constitución de 1978. Ese es un hecho constatado y constatable. Hecho que, por lo demás, llama poderosamente la atención, dado que el texto constitucional supuso una apertura incuestionable sobre la distribución del poder territorial y ese fortalecimiento del poder público local parecía exigir un fortalecimiento de los medios económicos con los que poder afrontar el robustecimiento de las nuevas competencias. Esos eran los aires que soplaban allá por 1978. Aires que el paso del tiempo ha ido atemperando, de forma que el evidente incremento del gasto público local ha ido acompañado también de un notorio incremento de los recursos públicos... aunque ese incremento proviene en muy buena medida de recursos cuya titularidad sigue siendo estatal. Las transferencias estatales siguen siendo un referente inamovible en la financiación de las entidades locales.

Allá por 1978 se convirtió en axioma aquello de que «sin autonomía financiera no hay autonomía política». El paso del tiempo ha novado sensiblemente la vieja aspiración tendente a la consecución de autonomía financiera local. Pese a que, formalmente, la doctrina jurisprudencial sigue insistiendo en que:

« ... el principio de autonomía financiera de los municipios (arts. 137 y $140 \mathrm{CE}$ ) exige que las Haciendas locales dispongan de medios financieros suficientes para poder ejercer, sin condicionamientos indebidos, las funciones que legalmente les han sido encomendadas, fundamentalmente, mediante tributos propios (art. $142 \mathrm{CE}$ ), pero que por estar sometidos al principio de reserva de ley (arts. 31.3 y 133.1 y 2 CE), corresponde al legislador estatal integrar las exigencias derivadas de esa reserva de ley como medio de preservar tanto la unidad del ordenamiento como una básica igualdad de posición de los contribuyentes [STC 233/1999, de 16 de diciembre, FJ 10.c)] ... » (STC 31 octubre 2019).

\section{AUTONOMÍA VERSUS SUFICIENCIA}

La actividad financiera pública se asienta en dos grandes sectores: el ingreso y el gasto público. En materia de gasto la evolución ha sido notable. El incremento generalizado es consecuencia obligada de la asunción de nuevas competencias. En el marco del ingreso las cosas son sensiblemente diferentes, toda vez que el sistema tributario local sigue asentado sobre las bases en que ya lo estaba con anterioridad a la entrada en vigor de la Constitución. De forma que la disponibilidad de recursos públicos propios, en sentido estricto, se ha alejado sensiblemente de las necesidades financieras que hoy tienen los entes locales.

Como ya tuvimos ocasión de señalar, «con posterioridad a la entrada en vigor de la Constitución... el Texto Refundido de la Ley de Haciendas Locales -Real Decreto Legislativo 2/2004, de 5 de marzo- actualmente vigente, se ha visto azacaneado reiteradamente por sentencias judiciales, alguna de las cuales, atendida su notable incidencia en la esfera de la recaudación local, ha obligado a que los poderes públicos se replanteen la necesidad de establecer un nuevo marco normativo que regule las Haciendas Locales. El quebranto del principio de seguridad jurídica en el ámbito tributario acaba siendo la factura a pagar por esa subordinación del poder tributario a las urgencias económicas...», concluyendo: «Mucho nos tememos que en los próximos años la lucha por la primacía del principio de seguridad jurídica en el ámbito tributario será uno de los objetivos a los que tendrán que hacer frente los tribunales europeos y señaladamente el TJUE» ("Cuarenta años de Derecho Tributario", en la obra colectiva "España constitucional. 1978-2018. Trayectorias y perspectivas", vol. II, págs. 1.199 y 2.014. Centro de Estudios Políticos y Constitucionales).

La realidad diaria confirma lo dicho. Veamos algún ejemplo de ello.

\section{LOS PERCANCES JUDICIALES Y EL DESEQUILIBRIO DEL SISTEMA DE INGRESOS PÚBLICOS LOCALES}

En el ámbito de los ingresos tributarios la realidad se caracteriza por dos notas esenciales: a) pervivencia, en sus grandes rasgos, de un sistema tributario preconstitucional y b) nula atención prestada por las Cortes Generales al diseño de un sistema tributario necesitado de reformas en sus puntos esenciales. 
El ejemplo más claro de ese desvalimiento del sistema tributario local lo tenemos muy reciente. En efecto, la Sentencia del Tribunal Constitucional 26/2017, de 16 de febrero (BOE 25 de marzo de 2017) inició un largo camino -que aún no ha llegado a su final- en virtud del cual se declaraba la inconstitucionalidad parcial del Impuesto municipal sobre Incremento del Valor de los Terrenos de Naturaleza Urbana -en adelante Impuesto sobre Plusvalía-, en la regulación dada al mismo por la Norma Foral 16/1989, reguladora del mismo en el Territorio histórico de Guipúzcoa. Unos días más tarde, el 1 de marzo de 2017, la STC 37/2017, de 1 de marzo (BOE 7 de abril de 2017), repetía la declaración de inconstitucionalidad en relación con la regulación que al mismo Impuesto le daba la Norma Foral 46/1989, reguladora del Impuesto en Álava.

En la primera de las Sentencias citadas, señala el TC:

«... es plenamente válida la opción de política legislativa dirigida a someter a tributación los incrementos de valor mediante el recurso a un sistema de cuantificación objetiva de capacidades económicas potenciales, en lugar de hacerlo en función de la efectiva capacidad económica puesta de manifiesto. Ahora bien, una vez hecha la precisión que antecede, es importante tener presente que una cosa es gravar una renta potencial (el incremento de valor que presumiblemente se produce con el paso del tiempo en todo terreno de naturaleza urbana) y otra muy distinta es someter a tributación una renta irreal, diferencia esta que es importante subrayar porque, si así fuese, es evidente que el precepto cuestionado sería contrario al principio constitucional de capacidad económica, dado que-como hemos venido señalando-dicho principio quiebra en aquellos supuestos en los que la capacidad económica gravada por el tributo sea no ya potencial sino inexistente o ficticia» (STC 295/2006, de 11 de octubre, FJ 5).

Pues bien, no cabe duda de que los preceptos cuestionados fingen, sin admitir prueba en contrario, que por el solo hecho de haber sido titular de un terreno de naturaleza urbana durante un determinado período temporal (entre uno y veinte años), se revela, en todo caso, un incremento de valor y, por tanto, una capacidad económica susceptible de imposición, impidiendo al ciudadano cumplir con su obligación de contribuir, no de cualquier manera, sino exclusivamente «de acuerdo con su capacidad económica» (art. $31.1 \mathrm{CE}$ ). Así las cosas, al establecer el legislador la ficción de que ha tenido lugar un incremento de valor susceptible de gravamen al momento de toda transmisión de un terreno por el solo hecho de haberlo mantenido el titular en su patrimonio durante un intervalo temporal dado, soslayando, no solo aquellos supuestos en los que no se haya producido ese incremento, sino incluso aquellos otros en los que se haya podido producir un decremento en el valor del terreno objeto de transmisión, lejos de someter a gravamen una capacidad económica susceptible de gravamen, les estaría haciendo tributar por una riqueza inexistente, en abierta contradicción con el principio de capacidad económica del citado art. 31.1 CE. Hemos de insistir en que, aunque el legislador ordinario goza de una amplia libertad de configuración normativa, su ejercicio debe efectuarse dentro del marco que la propia Constitución delimita, y, concretamente y como hemos señalado con anterioridad, con respeto al principio de capacidad económica al que llama el art. 31.1 CE, como fundamento de todo impuesto. De este modo, aunque el legislador establezca impuestos que "estén orientados al cumplimiento de fines o a la satisfacción de intereses públicos que la Constitución preconiza o garantiza» (SSTC 37/1987, de 26 de marzo, FJ 13, y 221/1992, de 11 de diciembre, FJ 4), como puede ser, en el caso que nos ocupa, dar cumplimiento a la previsión del art. $47 \mathrm{CE}$, en ningún caso puede hacerlo desconociendo o contradiciendo el principio de capacidad económica (STC 19/2012, de 15 de febrero, FJ 3), degenerando su originaria libertad de configuración en una indeseable arbitrariedad al gravarse «en todo o en parte rentas aparentes, no reales» [SSTC 221/1992, de 11 de diciembre, FJ 5.c), y 194/2000, de 19 de julio, FJ 8].

En definitiva, el tratamiento que los arts. 4 y 7.4 de la Norma Foral 16/1989 otorgan a los supuestos de no incremento o, incluso, de decremento, en el valor de los terrenos de naturaleza urbana, carece de toda justificación razonable en la medida en que, al imponer a los sujetos pasivos del impuesto la obligación de soportar la misma carga tributaria que corresponde a las situaciones de incrementos derivados del paso del tiempo, se están sometiendo a tributación situaciones de hecho inexpresivas de capacidad económica, lo que contradice frontalmente el principio de capacidad económica que la Constitución garantiza en el art. 31.1. De esta manera, los preceptos enjuiciados deben ser declarados inconstitucionales, aunque exclusivamente en la medida que no han previsto excluir del tributo a las situaciones inexpresivas de capacidad económica por inexistencia de incrementos de valor. (FJ 3). 


\section{En consecuencia:}

- El Impuesto no es inconstitucional en su configuración actual... salvo en aquellos casos en que grave situaciones que no son indicativas de capacidad económica.

- «No es posible asumir la interpretación salvadora de la norma cuestionada que se propone porque, al haberse establecido un método objetivo de cuantificación del incremento de valor, la normativa reguladora no admite como posibilidad ni la eventual inexistencia de un incremento ni la posible presencia de un decremento (el incremento se genera, en todo caso, por la mera titularidad de un terreno de naturaleza urbana durante un período temporal dado, determinándose mediante la aplicación automática al valor catastral del suelo en el momento de la transmisión de los coeficientes previstos en el art. 4.3 de la Norma Foral 16/1989). Es más, tampoco permite, siquiera, la determinación de un incremento distinto del derivado de "la aplicación correcta de las normas reguladoras del impuesto" (art. 7.4 de la Norma Foral 16/1989)» (FJ 6).

- La forma en que debe admitirse la existencia o no de capacidad económica susceptible de ser gravada corresponde al Legislador.

"... la forma de determinar la existencia o no de un incremento susceptible de ser sometido a tributación es algo que sólo corresponde al legislador, en su libertad de configuración normativa, a partir de la publicación de esta Sentencia, llevando a cabo las modificaciones o adaptaciones pertinentes en el régimen legal del impuesto que permitan arbitrar el modo de no someter a tributación las situaciones de inexistencia de incremento de valor de los terrenos de naturaleza urbana» (FJ 7).

Como era de esperar, apenas pasado un mes, el Pleno del Tribunal Constitucional, resolviendo una cuestión de inconstitucionalidad promovida por el Juzgado de lo Contencioso-Administrativo núm. 1 de Jerez de la Frontera, en relación con el artículo 107 del texto refundido de la Ley Reguladora de las Haciendas Locales, aprobado por el Real Decreto Legislativo 2/2004, de 5 de marzo, dictó una nueva Sentencia en la que recogiendo la doctrina mantenida en las dos anteriores extrapolaba ya al ordenamiento común las conclusiones alcanzadas en aquellas: STC 59/2017, de 11 de mayo (Ponente: A. Ollero Tassara)

Como era de esperar, dadas las incertidumbres que seguían vivas tras los pronunciamientos del Tribunal Constitucional, los juzgados y Tribunales del orden contencioso-administrativo siguieron pronunciándose de forma muy distinta y claramente contradictoria. Al punto que el Tribunal Supremo tuvo que fijar la doctrina que debía aplicarse a la luz de la doctrina constitucional. Es lo que hizo mediante Sentencia de 9 de julio de 2018 (rec. 6226/2017. Ponente: A. Aguallo).

En dicha Sentencia, el Tribunal Supremo insufló aire en los pulmones de los Ayuntamientos españoles, al considerar que el Impuesto podía seguir liquidándose, salvo que el obligado tributario probara la inexistencia de incremento de valor de los terrenos.

De una parte, consideró el Alto Tribunal que los artículos que regulan la cuantificación de la base imponible del Impuesto -arts. 107.1 y 107.2 a) del TRLHL- a tenor de la interpretación que debe darse al fallo y fundamento jurídico 5 de la STC 59/2017, «adolecen solo de una inconstitucionalidad y nulidad parcial».

En consecuencia, no procede acceder a la rectificación de las autoliquidaciones del IIVTNU y, por tanto, a la devolución de los ingresos efectuados por dicho concepto, en aquellos casos en los que no se acredita por el obligado tributario la inexistencia de incremento de valor de los terrenos de naturaleza urbana, supuestos en los que los artículos 107.1 y 107.2 a) del texto refundido de la Ley Reguladora de las Haciendas Locales (TRLHL) resultan constitucionales y, por consiguiente, los ingresos, debidos.

«En este sentido, son constitucionales y resultan, pues, plenamente aplicables, en todos aquellos supuestos en los que el obligado tributario no ha logrado acreditar (...) que la transmisión de la propiedad de los terrenos por cualquier título (o la constitución o transmisión de cualquier derecho real de goce, limitativo del dominio, sobre los referidos terrenos) no ha puesto de manifiesto un incremento de su valor o, lo que es igual, una capacidad económica susceptible de ser gravada con fundamento en el artículo $31.1 \mathrm{CE}$.

De otra parte, entiende que el «artículo 110.4 del TRLHL es inconstitucional y nulo en todo caso (inconstitucionalidad total) porque, como señala la STC 59/2017, "no permite acreditar un resultado diferente al 
resultante de la aplicación de las reglas de valoración que contiene", o, dicho de otro modo, porque "impide a los sujetos pasivos que puedan acreditar la existencia de una situación inexpresiva de capacidad económica (SSTC 26/2017, FJ 7, y 37/2017, FJ 5)"».

En relación con la prueba de la inexistencia de una plusvalía real y efectiva obtenida en la transmisión del terrero, considera el tribunal,

- corresponde «al obligado tributario probar la inexistencia de incremento de valor del terreno onerosamente transmitido»;

- para acreditar que no ha existido la plusvalía gravada por el IIVTNU «podrá el sujeto pasivo ofrecer cualquier principio de prueba, que al menos indiciariamente permita apreciarla (como es, por ejemplo, la diferencia entre el valor de adquisición y el de transmisión que se refleja en las correspondientes escrituras públicas)»;

- aportada «por el obligado tributario la prueba de que el terreno no ha aumentado de valor, deberá ser la Administración la que pruebe en contra de dichas pretensiones para poder aplicar los preceptos del TRLHL que el fallo de la STC 59/2017 ha dejado en vigor en caso de plusvalía».

- Contra el resultado de la valoración de la prueba efectuada por la Administración en el seno del procedimiento tributario correspondiente, el obligado tributario dispondrá de los medios de defensa que se le reconocen en vía administrativa y, posteriormente, en sede judicial. En la vía contencioso-administrativa la prueba de la inexistencia de plusvalía real será apreciada por los Tribunales de acuerdo con lo establecido en los artículos 60 y 61 LJCA y, en último término, y tal y como dispone el artículo 60.4 LJCA, de conformidad con las normas del Código Civil y de la Ley de Enjuiciamiento Civil.

- en la medida en que la existencia de una plusvalía real y efectiva resulta perfectamente constatable sobre la base del empleo de los medios de comprobación que establece la Ley General Tributaria en los artículos 105 y siguientes, medios que permiten rechazar que la norma autorice a la Administración para decidir con entera libertad el valor real del terreno onerosamente transmitido, no existe -en los casos en los que se liquida el IIVTNU- vulneración de la reserva de ley tributaria recogida en los artículos 31.3 y 133.1 CE, ni quiebra alguna del principio de seguridad jurídica (art. 9.3 CE).

Dos eran, como muy atinadamente señaló Rubio de Urquía, las contradicciones pendientes de resolver:

- acudir a valores reales para determinar la existencia o de un incremento de valor del terreno, mientras se acude a un valor administrativo -valor catastral, corregido por un coeficiente que tenga en cuenta el número de años en que se han generado las plusvalías- para cuantificar el importe del incremento de valor producido.

$\mathrm{O}$, lo que es lo mismo: se declara inconstitucional el gravamen cuando no existe incremento de valor... pero se declara ajustado a la Constitución cuantificar ese incremento de acuerdo con un método que puede... o no ajustarse a la situación realmente gravada.

- Someter a gravamen todo incremento real del valor del terreno para... a renglón seguido cuantificar el mismo de acuerdo no con su importe sino con la extensión del plazo de generación del mismo. (Editorial núm. 136 de la Revista Tributos locales: "El alcance de la declaración de inconstitucionalidad del Impuesto sobre el Incremento de Valor de los Terrenos de Naturaleza Urbana").

Pendientes las contradicciones apuntadas, la historia continúa. Así, mediante Auto 7591/2019, de 1 de julio de 2019 (rec. casación 981/2018. Ponente: A. Aguallo) el Tribunal Supremo eleva al Tribunal Constitucional, muy razonadamente, una nueva cuestión de inconstitucionalidad, en los siguientes términos:

«Plantear al Tribunal Constitucional cuestión de inconstitucionalidad respecto de los artículos 107.1, 107.2 a) y 107.4 del Real Decreto Legislativo 2/2004, de 5 de marzo, por el que se aprueba el Texto Refundido de la Ley Reguladora de las Haciendas Locales (BOE de 9 de marzo de 2004), habida cuenta de su eventual oposición a los principios de capacidad económica y, específicamente, de prohibición de confiscatoriedad, que proclama el artículo 31.1 CE». 
En los Antecedentes de hecho -segundo- concreta el Tribunal sus dudas sobre la constitucionalidad de tales preceptos:

«Nuestras dudas, muy sucintamente, se sustentan en los siguientes razonamientos:

a) En los preceptos expresados se enuncia la regla de cálculo de la base imponible del IIVTNU y se fijan los dos elementos objetivos precisos para su determinación (el valor del terreno en el momento del devengo por referencia a su valor catastral y el porcentaje anual de incremento según el número de años de permanencia del bien en el patrimonio del contribuyente), sin que se tenga en cuenta en absoluto el importe de la plusvalía realmente obtenida por el sujeto pasivo con ocasión de la transmisión onerosa.

b) La aplicación de esa forma de determinación de la base imponible puede dar lugar -y, de hecho, así sucede en el asunto que analizamos- a que la plusvalía efectivamente obtenida como consecuencia de la transmisión onerosa de un inmueble sea de importe inferior -con frecuencia, incluso, notablemente inferior- a la cuota tributaria que resulta de la aplicación de aquellas reglas.

c) Y si ello es así, es posible -y de ahí nuestra duda sobre la constitucionalidad de aquellos preceptos- que la forma que ha empleado el legislador para diseñar los elementos de cuantificación del tributo agote la riqueza imponible que está en la base de la imposición, de forma tal que podría producirse un resultado confiscatorio que incide negativamente en la prohibición constitucional que establece el artículo 31.1 CE, sobre todo si, como aquí sucede, como consecuencia de aquel diseño legal de los elementos de cuantificación de la prestación (o de alguno de ellos), la cuantía de la deuda tributaria exigida al sujeto pasivo, no solo agota o consume el importe de la riqueza que se somete a gravamen, sino que lo supera.

d) Es evidente que de la constitucionalidad de tales preceptos dependerá la solución del litigio que nos ocupa: la cuota girada al contribuyente (6.902,25 euros) por una plusvalía acreditada de 3.950 euros habrá de reputarse conforme a Derecho si los artículos citados se consideran ajustados a la Constitución y disconforme con el ordenamiento jurídico si se aprecia la confiscatoriedad cuya concurrencia planteamos a las partes y al Ministerio Fiscal a través de esta resolución».

En este descontrolado ir y venir a que han dado lugar las Sentencias del TC de 2017, ya se ha emitido una nueva Sentencia del Pleno del Tribunal Constitucional de 31 de octubre de 2019 (Ponente: P. GonzálezTrevijano), resolviendo la cuestión de inconstitucionalidad núm. 1020/2019, elevada por el Juzgado de lo Contencioso-Administrativo núm. 32 de Madrid, relativa a un caso en el que la ganancia patrimonial neta ascendía a 3.473, 90 euros, mientras que la cuota tributaria se elevaba a 3.560, 02 euros . En dicha Sentencia, concluye el Tribunal que:

«La declaración de inconstitucionalidad. La situación que ha dado lugar al planteamiento de la presente cuestión de inconstitucionalidad no puede considerarse en modo alguno como excepcional y, por tanto, el efecto negativo que provoca no es posible asumirlo como algo inevitable en el marco de la generalidad de la norma. Antes al contrario, se produce en relación con supuestos generales perfectamente definibles como categoría conceptual, razón por la cual, la legítima finalidad perseguida por la norma no puede prevalecer frente a las concretas disfunciones que genera, contrarias, como hemos visto, al principio de capacidad económica y a la prohibición de confiscatoriedad (art. 31.1 CE). En consecuencia, debe estimarse la presente cuestión de inconstitucionalidad... y, en consecuencia, declarar que el art. 107.4 del texto refundido de la Ley Reguladora de las Haciendas Locales, aprobado por el Real Decreto Legislativo 2/2004, de 5 de marzo, es inconstitucional por vulnerar el principio de capacidad económica y la prohibición de confiscatoriedad, uno y otra consagrados en el art. 31.1 CE, en aquellos supuestos en los que la cuota a pagar es superior al incremento patrimonial obtenido por el contribuyente» (FJ 5).

Eso sí, comienzan las matizaciones (FJ 5):

a) «El alcance de la declaración: la anterior declaración de inconstitucionalidad no puede serlo, sin embargo, en todo caso, lo que privaría a las entidades locales del gravamen de capacidades económicas reales. En coherencia con la declaración parcial de inconstitucionalidad que hizo la STC 59/2017, el art. 107.4 TRLHL debe serlo únicamente en aquellos 
casos en los que la cuota a satisfacer es superior al incremento patrimonial realmente obtenido por el contribuyente».

b) «Eso sí, la inconstitucionalidad así apreciada no puede extenderse, sin embargo, como pretende el órgano judicial, al art. 108.1 TRLHL (tipo de gravamen), pues el vicio declarado se halla exclusivamente en la forma de determinar la base imponible y no en la de calcular la cuota tributaria».

c) «Ha de añadirse una precisión sobre el alcance concreto del fallo. Por exigencia del principio de seguridad jurídica (art. 9.3 CE), y al igual que hemos hecho en otras ocasiones (por todas, SSTC 22/2015 de 16 de febrero, FJ 5; y 73/2017, de 8 de junio, FJ 6), únicamente han de considerarse situaciones susceptibles de ser revisadas con fundamento en esta Sentencia aquellas que, a la fecha de publicación de la misma, no hayan adquirido firmeza por haber sido impugnadas en tiempo y forma, y no haber recaído todavía en ellas una resolución administrativa o judicial firme».

\section{LA DESIDIA DEL LEGISLADOR ESTATAL}

La llamada de auxilio que el TC hizo al Legislador en la Sentencia 59/2017 al Legislador está pendiente de respuesta aun hoy -24 de diciembre de 2019-. Llamada que ha vuelto a repetirse, sin el menor éxito, en la referida Sentencia del Pleno del Tribunal Constitucional de 31 de octubre de 2019:

"La necesaria intervención del legislador: es importante señalar que una vez declarados inconstitucionales, primero los arts. 107.1, 107.2 a) y 110.4 del TRLHL por la STC 59/2017, de 11 de mayo, y ahora el art. 107.4 TRLHL por la presente sentencia, es tarea del legislador, en el ejercicio de su libertad de configuración normativa, realizar la adaptación del régimen legal del impuesto a las exigencias constitucionales... No hay que olvidar que, de conformidad con el art. 31.1 CE, los ciudadanos no solo tienen el deber constitucional de contribuir al sostenimiento de los gastos públicos, sino también el derecho de hacerlo, no de cualquier manera, sino únicamente "con arreglo a la ley" y exclusivamente "de acuerdo con su capacidad económica". Sólo al legislador le es dado, entonces, regular esa contribución y la forma de adecuarla a la capacidad económica de cada cual, dado que a fecha de hoy han trascurrido más de dos años desde la publicación de la STC 59/2017, de 11 de mayo (BOE núm. 142, de 15 de junio), sin que haya acomodado el impuesto a las exigencias constitucionales. Es importante subrayar que el principio de seguridad jurídica (art. 9.3 CE) exige no solo la claridad y certeza sobre el ordenamiento jurídico aplicable, sino también la legítima confianza y la previsibilidad en sus efectos, entendida como la expectativa razonablemente fundada del ciudadano de cuál ha de ser la actuación del poder en la aplicación del Derecho (STC 135/2018, de 13 de diciembre, FJ 5) [FJ 5.b)]».

Más allá de la inseguridad jurídica generada a raíz de los distintos pronunciamientos del Tribunal Constitucional sobre el Impuesto de Plusvalía -pronunciamientos que van a seguir como es de prever-, la conclusión que cabe sentar es clara: la desidia legislativa supone una confirmación adicional a la incuria que el Legislador español ha mantenido en relación al sistema tributario local, obviando así uno de los dos elementos esenciales -ingreso- sobre el que se asienta la autonomía financiera local.

Frente a la apuntada desidia del Legislador estatal, las Diputaciones Forales sí han actuado. El Decreto Foral-Norma 2/2017, de 28 de marzo, modifica el IIVTNU (Guipúzcoa) y el Decreto Normativo de Urgencia Fiscal 3/2017, del Consejo de Gobierno Foral de 28 de marzo, convalidada por la Norma foral 8/2017 (Álava), acatan las sentencias del Constitucional y dictan las disposiciones que entienden deben aplicarse tras los pronunciamientos del Tribunal Constitucional.

\section{LA AUTONOMÍA LOCAL EN MATERIA DE GASTO}

En el ámbito del gasto público local las cosas han evolucionado de forma sensiblemente diferente. Al punto que, como de forma reiterada ha reconocido la jurisprudencia, ste es un campo en el que sí se manifiesta con claridad el respeto a las exigencias ínsitas en el concepto de autonomía financiera local. 
Así, en la STC 104/2000, de 13 de abril (Sentencia del Pleno. Ponente: M. Jiménez de Parga), reiterando una doctrina ya consolidada, se afirma:

«... el principio de autonomía (para "la gestión de sus respectivos intereses", según el art. 137 $\mathrm{CE})$ que preside la organización territorial del Estado, configura uno de los pilares básicos del ordenamiento constitucional (STC 32/1981, de 28 de julio, FJ 3), ofreciendo una vertiente económica relevante ya que, aun cuando tenga un carácter instrumental, la amplitud de los medios determina la posibilidad real de alcanzar los fines (STC 135/1992, de 5 de octubre, FJ 8). La autonomía de los entes locales va, entonces, estrechamente ligada a su suficiencia financiera, por cuanto exige la plena disposición de medios financieros para poder ejercer, sin condicionamientos indebidos y en toda su extensión, las funciones que legalmente les han sido encomendadas (SSTC 179/1985, de 19 de diciembre, FJ 3; 63/1986, de 21 de mayo, FJ 11; 201/1988, de 27 de octubre, FJ 4; 96/1990, de 24 de mayo, FJ 7 y 14; 13/1992, de 6 de febrero, FJ 6; 132/1992, de 28 de septiembre, FJ 8; 237/1992, de 15 de diciembre, FJ 6; 331/1993, de 12 de noviembre, FJ 2 y 3; 68/1996, de 18 de abril, FJ 10; y 171/1996, de 30 de octubre, FJ 5; 166/1998, de 15 de julio, FJ 10; y 233/1999, de 16 de diciembre, FJ 22); es decir, para posibilitar y garantizar, en definitiva, el ejercicio de la autonomía constitucionalmente reconocido en los arts. 137, 140 y 141 CE (SSTC 96/1990, de 24 de mayo, FJ 7; 331/1993, de 12 de noviembre, FJ 2 b); 233/1999, de 16 de diciembre, FJ 22; y ATC 382/1993, de 1 de diciembre, FJ 4).

Aunque el soporte material de la autonomía financiera son los ingresos y en tal sentido la Constitución configura como principio la suficiencia de recursos (en el art. 142), sin embargo, tiene un primer límite "en el marco de las disponibilidades presupuestarias" (STC 96/1990, de 24 de mayo, FJ 7). Si a esto le unimos que la autonomía financiera está configurada más por relación a la vertiente del gasto (como capacidad para gastar, y si acaso, a la de las transferencias de ingresos procedentes de la Hacienda estatal y que constituyen un derecho de crédito frente a ésta a favor de los entes locales) que con relación al ingreso -como capacidad para articular un sistema suficiente de ingresos-, llegamos a la conclusión de que la autonomía financiera está primordialmente conectada, de un lado, con la capacidad del sistema tributario como fuente principal de los ingresos de derecho público, pero, de otro lado, y dada la insuficiencia de éste, a través de la participación en los ingresos del Estado» (FJ 4).

Materia ésta en la que, además, ha podido constatarse cómo las Entidades Locales han sido obedientes al mandato de estabilidad financiera impuesto por la reforma del art. 135 de la Constitución el 27 de septiembre de 2011. Vid. Ley $27 / 2013$, de Racionalidad y Sostenibilidad de la Administración Local, dictada en desarrollo del art. 135 CE y de la Ley Orgánica 2/2012, de 27 de abril, de Estabilidad Presupuestaria y Sostenibilidad Financiera.

Como señaló Rodríguez Bereijo «La reforma constitucional del art. 135 CE no responde a un mero capricho o al puro oportunismo político. Existen pocas dudas del grave desajuste de nuestras cuentas públicas frente a los compromisos que resultan del Pacto de Estabilidad y Crecimiento de la Unión Europea en una coyuntura financiera internacional (la crisis de la deuda soberana) que amenazaba directamente a España» ("Los «silencios» (art. 2) y la «reserva de lo posible» (art. 135) en la Constitución española", en la obra colectiva "España constitucional 1978-2018. Trayectorias y perspectivas", vol. I, pág. 846. Centro de Estudios Políticos y Constitucionales).

Esta autonomía de gasto no impide, por otra parte, la existencia de límites establecidos tanto por el Estado como por las Comunidades Autónomas.

Doctrina también reiterada, de la que es claro exponente la STC 109/1998, de 21 de mayo (Sentencia del Pleno. Ponente: P. García Manzano):

«Por ello, la facultad de aprobar los presupuestos es, ciertamente, como venimos indicando desde la STC 32/1981, "una potestad decisoria fundamental sin la que no cabe hablar de autonomía" y cuya privación, por consiguiente, "ha de considerarse contraria a la Constitución, especialmente en su art. 142" (fundamento jurídico $8 .^{\circ}$; en términos similares, STC 27/1987, fundamento jurídico $\left.7 .^{\circ}\right)$. Dando un paso más, en la STC 237/1992 se profundizó en el alcance de la autonomía de gasto de las Corporaciones locales, considerando aplicable en lo esencial la doctrina inicialmente vertida en torno a las Comunidades Autónomas, según la cual la misma entraña, en 
línea de principio, la plena disponibilidad de sus ingresos, sin condicionamientos indebidos y en toda su extensión, para poder ejercer las competencias propias; pero ello en el bien entendido de que "esa libertad para establecer el plan de ingresos y gastos, en definitiva el presupuesto, no se establece constitucionalmente con carácter absoluto" (fundamento jurídico 6. ${ }^{\circ}$ ).

Ahora bien, bajo el prisma de los arts. 137 y 142 CE, el ámbito sobre el que se proyecta la autonomía de gasto provincial no ha de concebirse como una esfera total y absolutamente resistente a cualquier mínima incidencia o afectación proveniente de otros niveles de gobierno. Tal y como antes señalamos respecto de la garantía institucional de la autonomía local, y ahora debemos lógicamente repetir en su concreta vertiente financiera, lo que la Constitución veda de una forma terminante y sin excepciones no es sino el menoscabo del núcleo esencial o reducto indisponible de la institución, estrictamente. En consecuencia, la autonomía financiera, en la vertiente del gasto, de la que gozan los Entes locales, -esto es, la capacidad genérica de determinar y ordenar, bajo su propia responsabilidad, los gastos necesarios para el desempeño de sus competencias- puede ser restringida por el Estado y las Comunidades Autónomas dentro de los límites establecidos en el bloque de la constitucionalidad, tal como sucede en este caso en virtud de las facultades coordinadoras que ostenta la Generalidad de Cataluña con la cobertura del Plan Único de Obras y Servicios» (FJ 10).

En el ámbito financiero local se reproduce también la asimetría denunciada unánimemente en el ámbito de la financiación de las Comunidades Autónomas, en virtud de la cual una creciente autonomía en el gasto se ve contrarrestada por un sistema de ingresos cada vez más dependientes del Estado.

Como ha señalado Rodríguez Bereijo «La falta de correspondencia (esquizofrenia más que asimetría) entre las responsabilidades de gasto y las responsabilidades de ingreso de las CC.AA constituye un factor de distorsión y de desequilibrio en el funcionamiento de la Hacienda General del Estado, y por tanto en el sistema de financiación autonómica que debería ser corregido no sólo por razones de autonomía política y financiera de las CC.AA, sino también por razones de una asignación racional y eficiente de los recursos públicos, acorde, por lo demás, con los principios constitucionales de equidad, eficiencia y economía del gasto público que consagra el art. 31.2 CE» (ob. cit. pág. 847).

\section{CONCLUSIONES}

1. El mandato del art. $142 \mathrm{CE}$ ha tenido un desigual desarrollo en materia de ingresos y gastos, de forma que mientras en el ámbito del gasto público se han tenido en cuenta las exigencias derivadas del respeto a la autonomía local, en el ámbito de los ingresos públicos esa exigencia se ha visto sensiblemente desleída.

2. En el ámbito del gasto público está asentada la doctrina constitucional en virtud de la cual:

a) El poder de gasto constituye un aspecto esencial de la denominada suficiencia financiera (Sentencias TC: 32/1981. FJ 4; 27/1987, FJ 7; 109/1998, FJ 10...).

b) La autonomía en materia de gasto se identifica como la plena disponibilidad para ejercer competencias propias.

c) Esa autonomía conlleva el poder de decisión sobre el destino de los fondos, sin condicionamientos indebidos (SSTC 109/1998, FJ 10; 104/2000, FJ 4; 48/2004, FJ 10...).

d) La autonomía de gasto puede reducirse de acuerdo con las exigencias del bloque de constitucionalidad (STC 109/1998. FJ 1. Leading case).

e) Al amparo de la Ley General de Estabilidad Presupuestaria no hay vulneración de la autonomía financiera local si se condiciona el endeudamiento a que el desequilibrio económico desaparezca en 3 ejercicios presupuestarios, dada la capacidad estatal para limitar el endeudamiento local al amparo del art. 149.11) y 13) CE (STC 134/2011, FJ 14.b).

3. La participación en tributos del Estado continúa siendo la fuente principal de ingresos de las Entidades Locales, de conformidad con la Ley 51/2002, de 27 de diciembre, de reforma de la Ley de Haciendas Locales.

4. La participación en ingresos estatales y las subvenciones incondicionadas -percibidas a través de las CC.AA- con criterios de repartos fijados por el Estado (SSTC 96/1990 y 331/1993) constituyen también una importante fuente de ingresos. 
5. Es constitucionalmente admisible la existencia de subvenciones condicionadas, siempre que sean complementarias y no afecten al bloque esencial de las competencias en materia de gasto.

6. La participación en tributos propios de las Comunidades Autónomas no han tenido el desarrollo que era previsible atendido tanto el texto del art. $142 \mathrm{CE}$ como los debates habidos en torno al proyecto de Constitución. En este punto se dejan sentir con especial intensidad las carencias imputables al sistema de financiación establecido por la LOFCA... cuya reforma parece nunca llegar.

7. El diseño de la normativa reguladora del sistema financiero local se ve decisivamente afectado por la renuencia del Tribunal Constitucional a entrar en el fondo de una materia -autonomía financiera local- que, calificada como garantía institucional, adolece de límites muy difusos, de forma que se trata de un concepto tendencialmente amplio, susceptible de extensión o reducción en función de las exigencias del bloque de constitucionalidad y de cuantos principios merecen también protección constitucional (SSTC 41/2016, 111/2016, 168/2016, 180/2016 y 44/2017).

Sobre el proceso creado por la LO 7/1999 -conflicto en defensa de la autonomía local-, cuya efectividad ha sido nula, vid. el trabajo de Tomás Font i Llovet "El municipio constitucional: balance y perspectivas de reforma", en la obra colectiva "España constitucional. 1978-2018. Trayectorias y perspectivas", vol. V, págs. 4.337 y ss. Concluye Font: «...lo cierto es que el conflicto en defensa de la autonomía local puede considerarse un experimento constitucionalmente fallido. El "Pacto local" de finales de los años 90 tuvo un precio, y fue la inoperancia del producto -defectuoso- que se ofreció al mundo local a cambio de evitar el incremento competencial de los municipios y la mejora de la financiación local que reclamaba el mundo local» (pág. 4.343). Como puede apreciarse... seguimos con los bastos.

\section{REFERENCIAS BIBLIOGRÁFICAS}

FONT I LLOVET, T. (2018): "El municipio constitucional: balance y perspectiva de reforma", en PENDÁS GARCÍA, B. (dir.); GONZÁLEZ HERNÁNDEZ, E.; RUBIO NÚÑEZ, R. (coords.): España constitucional (1978-2018): trayectorias y perspectivas, vol. V, págs. 4.337 y ss. Madrid: Centro de Estudios Políticos y Constitucionales. ISBN 978-84-259-1761-5.

MARTÍN QUERALT, J. B. (2018): "Cuarenta años de Derecho Tributario", en PENDÁS GARCÍA, B. (dir.); GONZÁLEZ HERNÁNDEZ, E.; RUBIO NÚÑEZ, R. (coords.): España constitucional (1978-2018): trayectorias y perspectivas vol. II, págs. 1.199 y 2.014. Madrid: Centro de Estudios Políticos y Constitucionales. ISBN 978-84-259-1761-5.

RODRÍGUEZ BEREIJO, A. (2018): "Los «silencios» (art.2) y «la reserva de lo posible» (art. 135) en la Constitución Española", en PENDÁS GARCíA, B. (dir.); GONZÁLEZ HERNÁNDEZ, E.; RUBIO NÚÑEZ, R. (coords.): España constitucional (1978-2018): trayectorias y perspectivas, vol. I, tomo 1, pág. 846. Madrid: Centro de Estudios Políticos y Constitucionales. ISBN 978-84-259-1761-5.

RUBIO DE URQUÍA, R. (2018): "El alcance de la declaración de inconstitucionalidad del Impuesto sobre el Incremento de Valor de los Terrenos de Naturaleza Urbana", en Revista Tributos Locales, núm. 136. 